\title{
Does the Sequencing of Exam Sections Impact Candidate Success on the CPA Exam?
}

\author{
Randall B. Bunker \\ University of North Alabama \\ Corey S. Cagle \\ University of North Alabama
}

\begin{abstract}
Accounting educators and CPA Exam candidates are always looking for ways to increase exam pass rates. While many studies have identified factors that increase exam performance, very little research has been done concerning the order in which CPA Exam sections should be taken by exam candidates. This study extends prior research by examining pass rates for individual CPA Exam sections. Findings indicate that while first-time candidates typically take the BEC section first, evidence suggests that it might be more beneficial to take the FAR section of the CPA Exam first.
\end{abstract}

Keywords: CPA exam, pass rates, certification, exam sections, public accounting

\section{INTRODUCTION}

Becoming a licensed Certified Public Accountant (CPA) is critical for a successful career in public accounting. One step toward earning a CPA license is passing the Uniform CPA Examination (CPA Exam). The CPA Exam is a professional licensing test which serves to safeguard the public interest by certifying that only qualified individuals become licensed CPAs. Public accounting firms often recruit for entry level positions that require new hires to be CPA Exam eligible upon graduation. The majority of states/jurisdictions require a minimum of 150 semester hours of higher education from an accredited university as a prerequisite to CPA certification. High pass rates on the CPA Exam provide evidence of having a quality accounting program and are used by universities to attract prospective students. With so much riding on successfully passing the CPA Exam, accounting educators and exam candidates are always looking for ways to increase CPA Exam pass rates.

The CPA Exam consists of four sections: Auditing and Attestation (AUD), Business Environment and Concepts (BEC), Financial Accounting and Reporting (FAR) and Regulation (REG). Prior research studies have identified several factors that increase overall CPA Exam performance, including factors such as: qualifications of accounting faculty, accounting faculty scholarly research productivity, highest degree level obtained for candidates, undergraduate grade point average, effectiveness of CPA Exam review courses, type of university accreditation, and the impact of taking CPA exam sections within one year of graduation, just to name a few. However, with the exception of Bline et al. (2016a), very little research has been done concerning the order in which CPA Exam sections should be taken by exam candidates. 
Becker CPA Exam review recommends students strongly consider taking FAR first because FAR has the lowest pass rate of the four CPA exam sections, and it covers the largest amount of content of any section (Becker 2020). They further noted that it might be preferable to start with FAR when candidates are fresh from their university studies. Becker (2020) suggests candidates take the CPA Exam in the following order: FAR, AUD, REG, and BEC, noting that FAR is a stepping stone to AUD and that BEC makes for a

good capstone because it covers concepts mentioned in the other three sections. Becker (2020) noted that students should not save FAR to the last section and suggested that students should complete the exam as quickly as possible after graduation because this led to the highest rates of success on the CPA Exam.

Using the CPA Exam as a post-curriculum assessment, Bunker and Cagle (2020) found that first-time CPA Exam candidates who took the CPA Exam within one year of graduation achieved higher overall pass rates and higher average exam scores than did first-time CPA Exam candidates who took the exam more than one year after graduation. The current study extends that research by examining the pass rates for each individual CPA Exam section. Using CPA Exam candidates from universities accredited by the Association to Advance Collegiate Schools of Business (AACSB) International, this study compares pass rates by section for first-time candidates taking the CPA Exam within one year of graduation to first-time candidates taking the CPA Exam more than one year after graduation. First-time candidates that took FAR within one year of graduation had a $15.20 \%$ higher average pass rate than did candidates that waited more than one year after graduation, which was the largest difference for any CPA Exam section, suggesting that the FAR section of the CPA exam should be taken first by exam candidates.

\section{BACKGROUND AND LITERATURE REVIEW}

The American Institute of Certified Public Accountants (AICPA) develops, maintains, and scores the CPA Exam. In partnership with the National Association of State Boards of Accountancy (NASBA), the CPA Exam is administered at Prometric test centers. CPA Exam candidates must pass all four sections within 18 months, earning a minimum score of 75 on each section. After successfully completing the CPA Exam, individuals must complete the 150 credit hours of education requirement and the work experience requirement as determined by the licensing state board. The U.S. Virgin Islands is the only U.S. jurisdiction that currently does not require at least 150 credit hours of education for licensure (AICPA 2020).

Data used in this study were collected for AACSB-accredited business schools. Colleges and universities often seek accreditation from independent organizations as a measure of the quality of the program and/or institution. AACSB International was founded in 1916 and is a leading accrediting organization for schools of business around the world. AACSB accreditation provides both a framework and processes that increase the likelihood of a school meeting its goals and the needs of students, faculty, employers, and other constituents; it is a general baseline of quality that encourages innovation and continuous improvement (Romero 2008). As of January 2021, there were 882-member institutions from 57 countries and territories that held AACSB accreditation (AACSB 2021). AACSB strives to continuously improve engagement among business, faculty, institutions, and students so that business education is aligned with the needs of business practice (AACSB 2021). In addition, AACSB accreditation provides benefits to the faculties and staffs of accredited schools by attracting higher quality students, providing greater research opportunities, and allowing for global recognition (AACSB 2021). Once accredited, member institutions must go through an evaluation process to maintain their membership status, typically once every five years.

Academic accounting programs often use CPA Exam results as a post-curriculum assessment tool. One of the first research studies that used CPA Exam results to measure the effectiveness of accounting programs was conducted by Marts et al. in 1988. Marts et al. (1988) compared candidates from AACSB accredited accounting programs, candidates from non-AACSB accredited programs, and candidates from programs that were AACSB accredited in business only. Their research concluded that graduates from AACSB accredited accounting programs performed significantly better than did graduates from non-AACSB accredited programs, but they did not find a significant difference between the two categories of AACSB 
accreditation. Prior research studies have identified various quantitative or qualitative factors that lead to increased pass rates on the CPA Exam. The following paragraphs review some of these studies.

Bunker and Cagle (2020) examined whether the time frame in which candidates sit for the CPA Exam has an impact on their success. Their study examined whether first-time candidates taking the CPA Exam within one year of graduation from college achieved comparable results as compared with first-time candidates taking the CPA Exam more than one year after graduation. Their results indicated that first-time CPA Exam candidates who took the CPA Exam within one year of graduation achieved higher overall pass rates and higher average exam scores, suggesting that timing does impact candidate success on the CPA Exam.

Bline et al. (2016a) examined whether the order in which candidates take the individual sections of the CPA Exam is related to their performance and whether certain factors may influence the likelihood that candidates take the examination sections in a specific order. Their research found evidence that the length of time needed to complete all four parts of the CPA exam differs by the order in which the parts are taken, concluding that the average candidate is likely to pass the CPA Exam most quickly when taking the FAR section of the examination first and least quickly when taking the BEC section first. They also noted that older candidates were less likely to take the FAR section first and that students may perceive that the FAR section is most relevant to their accounting coursework and may, therefore, choose to take this section as close to the completion of their studies as possible.

Conteh and Oke (2019) conducted a survey study that examined CPA Exam pass rates and suggested a redesign of the accounting curriculum. Their study examined the impact of the 150 credit hours of education requirement, increasing intermediate accounting courses to at least eight credit hours, and increasing auditing and advanced accounting to six credit hours each. They also examined the inclusion of governmental accounting, regulations, and business environment and concepts as part of the accounting curriculum. Conteh and Oke (2019) concluded that undergraduate auditing should be increased from three to six credit hours and that intermediate accounting should be increased to at least eight credit hours.

Rau et al. (2019) examined the impact on CPA Exam performance of accounting faculty credentials and candidates with graduate degrees versus undergraduate degrees. They concluded the percentage of accounting faculty with a doctoral degree and the percentage of CPA-certified accounting faculty were both significantly associated with improved CPA Exam performance. They also noted that candidates with graduate degrees significantly outperformed candidates with only undergraduate degrees on the CPA Exam. Without mentioning specific courses, they also noted that CPA Exam candidates benefited from additional accounting coursework. Rau et al. (2019) focused primarily on CPA Exam pass rates, but they achieved similar results when using CPA Exam score as the dependent variable.

Nagle et al. (2018) examined institutional variables that could potentially impact performance on the CPA Exam, including type of accreditation, admissions selectivity, accounting faculty credentials, and type of institution (private or public). They concluded that the completion of a graduate degree was significantly associated with higher CPA Exam pass rates. Nagle et al. (2018) also concluded that institutional variables including accreditation type, admissions selectivity, and the percentage of accounting faculty holding a CPA license were significant. In addition, their research concluded that other institutional variables including research ranking, institution type, and the percentage of accounting faculty holding a doctoral degree were not significant.

Reviewing high school students' success in advanced placement (AP) courses may assist college recruiters in identifying high school students that will perform well in a college accounting curriculum as well as success on the CPA Exam according to Ugrin and Honn (2018). Their study reviewed students' participation and achievement in AP courses during high school and the association with CPA Exam performance. Positive results were found that indicated that high school students who successfully completed AP courses and related exams experienced comparatively greater success on the CPA Exam versus students who did not complete or pass AP courses in high school. In addition, AP courses that included emphasis on higher-order thinking skills, also produced greater CPA Exam success (Ugrin and Honn 2018). 
Eames et al. (2018) examined accelerated post-graduate accounting certificate programs and whether these programs provide an equivalent accounting education (in terms of CPA Exam performance) to that of a traditional undergraduate program. They compared two accelerated accounting certificate programs with a traditional undergraduate program that shared the same or similar instructors, materials, course coverage, time in the classroom, class sizes, and pedagogy. Their results found no differences between the accelerated and traditional program alumni in ultimate pass rates and the number of attempts required to pass. According to Eames et al. (2018), accounting grade point average (GPA) is positively associated with passing the CPA Exam and inversely associated with the number of attempts and time required to pass the CPA Exam. They found little significance for the other explanatory variables tested and concluded that accounting GPA is the dominant indicator of CPA Exam success. In addition, they noted that public accounting experience and the availability of an employer bonus for passing the CPA Exam on a timely basis were associated with attempting the CPA Exam, but not with passing the CPA Exam, passing in fewer attempts, or passing sooner after graduation.

Shough et al. (2018) examined the curricula of AACSB accredited Master of Accounting (MACC) programs and the impact curricula had on CPA Exam pass rates. Their study examined (a) commonalities and differences among MACC programs, (b) relationships between university resource levels and CPA Exam pass rates, and (c) whether programs with a flexible curriculum reported higher CPA Exam pass rates. They concluded that higher resource levels are correlated with better CPA Exam performance and that for high-resource and low-resource (but not medium-resource) schools, greater curriculum leeway in elective customization is correlated with better CPA Exam performance.

Gaynor and Askew (2017) conducted the CPA Candidate Success Research Project to identify areas to help increase CPA Exam performance. They suggested that incorporating on-campus CPA review classes, creating on campus CPA study room/testing lab, and appointing a faculty member to serve as an academic champion of the CPA Exam would improve CPA Exam success rates. Gaynor and Askew (2017) focused on identifying best practices that accounting programs could employ to assist their students in achieving success on the CPA Exam and believed that success on the CPA Exam could easily be replicated at other schools.

Menk et al. (2017) examined CPA Exam performance for candidates completing a graduate degree program compared with candidates who only completed an undergraduate degree. They concluded that CPA Exam average scores and average pass rates increased for candidates who completed graduate degrees versus candidates who only completed undergraduate degrees. Menk et al. (2017) also confirmed prior research results that school selectivity and the type of school accreditation impacted CPA Exam performance.

Bline et al. (2016b) investigated a number of faculty-specific characteristics to determine their impact, if any, on CPA Exam performance. The following characteristics were included as part of their study: (1) research and teaching specializations of accounting program faculty, (2) research productivity of a program's faculty, and (3) percentage of CPA-certified instructors as members of its faculty. They concluded that a significant and positive relationship exists between candidate CPA Exam performance for both faculty research productivity and faculty CPA certification status. Bline et al. (2016b) also noted that a significant positive relationship exists between faculty specialization and candidate CPA Exam performance across all four sections of the exam. They concluded that schools should recruit CPA-certified faculty with teaching interests related to CPA Exam content and increase resources allocated to faculty research, since faculty research productivity also positively influences CPA Exam scores.

\section{RESEARCH METHODOLOGY AND RESULTS}

Since 1985, the National Association of State Boards of Accountancy (NASBA) has gathered data on the CPA Exam. NASBA publishes uniform CPA Examination candidate performance reports with the cooperation of the AICPA and through the voluntary participation of candidates and their individual State Boards of Accountancy, which provide data. As a result of the voluntary nature of some of the data sought, some results are incomplete or unavailable. This research study used NASBA data for the CPA Exam from 
2017, which was the most recent year that first-time testing events within one year of graduation were reported separately.

Data were collected for AACSB accredited business schools by CPA Exam section (AUD, BEC, FAR, REG) for all first-time testing events and for first-time testing events within one year of graduation (Appendix B-1 and Appendix C-1 from the 2017 uniform CPA Examination candidate performance report). Data for each AACSB accredited institution included both graduate and undergraduate degrees. Calculations were performed for each CPA Exam section to remove first-time testing events within one year of graduation from all first-time testing events, to create the category of first-time testing events more than one year after graduation. The overall pass rates for each section of the CPA Exam were collected for each available AACSB accredited institution and were used as the dependent variables in this study. The final sample included a total of 376 AACSB accredited institutions that had observations for first-time testing events and for first-time testing events within one year of graduation for each section of the CPA Exam. The final sample included a total of 40,012 first-time candidates taking 80,421 sections of the CPA Exam.

Using t-tests, this study compared CPA Exam overall pass rate results by section for first-time candidates from AACSB accredited institutions taking an exam section within one year of graduation to results of first-time candidates taking an exam section more than one year after graduation. See Table 1 for results by CPA Exam section. For first-time candidates taking the AUD exam section for the first time within one year of graduation, the overall pass rate was $61.35 \%$. For first-time candidates taking the AUD exam section for the first time more than one year after graduation, the overall pass rate was $52.14 \%$. For first-time candidates taking the BEC exam section for the first time within one year of graduation, the overall pass rate was $74.73 \%$. For first-time candidates taking the BEC exam section for the first time more than one year after graduation, the overall pass rate was $61.15 \%$. For first-time candidates taking the FAR exam section for the first time within one year of graduation, the overall pass rate was $62.18 \%$. For firsttime candidates taking the FAR exam section for the first time more than one year after graduation, the overall pass rate was $46.98 \%$. For first-time candidates taking the REG exam section for the first time within one year of graduation, the overall pass rate was $61.15 \%$. For first-time candidates taking the REG exam section for the first time more than one year after graduation, the overall pass rate was $50.43 \%$. Results for each dependent variable by CPA Exam section were statistically significant at $p$-value $<0.0001$.

These results confirm prior findings that candidates are more successful when taking the CPA Exam within one year of graduation. These results also show that the FAR section has the largest disparity in pass rate for candidates taking the exam within one year of graduation. First-time candidates that took FAR within one year of graduation had a $15.20 \%$ higher pass rate than candidates that waited more than one year after graduation, supporting Bline et al. (2016a) and Becker (2020) that FAR should be the first CPA Exam section completed by candidates.

Noteworthy from the results is that while prior publications consistently suggest candidates take the FAR section of the exam first, candidates taking the exam within one year of graduation instead tend to take the BEC section first. Research results show that within one year of graduation, 8,550 sections of BEC were taken by exam candidates as compared with 7,448 sections of FAR (a difference of 1,102). BEC has the highest pass rate for students in either of the two categories - students taking the exam within one year of graduation and students taking the exam a year or more beyond graduation. Perhaps the most striking data from these results is that for students taking the exam within one year of graduation, FAR results yield the second highest pass rate after BEC. However, for students taking the exam a year or more after graduation, FAR has the lowest pass rates of the four exam parts. This coupled with the fact that for candidates taking the exam within a year versus candidates taking the exam a year or more after graduation, FAR exhibits the largest percentage pass rate decline $(62.18 \%$ to $46.98 \%)$ of any of the four exam parts certainly has implications for future test takers. 


\section{TABLE 1}

\section{CPA EXAM RESULTS BY SECTION FOR CANDIDATES FROM AACSB ACCREDITED SCHOOLS OF BUSINESS TAKING THE EXAM WITHIN 1 YEAR OF GRADUATION COMPARED TO CANDIDATES TAKING THE EXAM MORE THAN 1 YEAR AFTER GRADUATION}

\begin{tabular}{|l|l|l|}
\hline Categoty & Within 1 year of graduation & More than 1 year after graduation \\
\hline AUD Pass Rate & $61.35 \%$ & $52.14 \%$ \\
\hline Number of AUD Sections & 7,079 & 12,890 \\
\hline P-value of t-test on Pass Rate & $<0.0001$ & $<0.0001$ \\
\hline BEC Pass Rate & $74.73 \%$ & $61.15 \%$ \\
\hline Number of BEC Sections & 8,550 & 11,928 \\
\hline P-value of t-test on Pass Rate & $<0.0001$ & $<0.0001$ \\
\hline FAR Pass Rate & $62.18 \%$ & $46.98 \%$ \\
\hline Number of FAR Sections & 7,448 & 12,755 \\
\hline P-value of t-test on Pass Rate & $<0.0001$ & $<0.0001$ \\
\hline REG Pass Rate & $61.15 \%$ & $50.43 \%$ \\
\hline Number of REG Sections & 6,977 & 12,794 \\
\hline P-value of t-test on Pass Rate & $<0.0001$ & $<0.0001$ \\
\hline Data collected from NASBA 2017 CPA Examination Candidate Performance book. \\
\hline
\end{tabular}

\section{CONCLUSION}

Becker CPA Exam review recommends candidates taking the CPA exam strongly consider taking FAR first, and other recent publications have also suggested this approach. This study has gathered evidence on the pass rates of the individual exam sections by comparing candidates taking the exam within one year of graduation to candidates taking the exam beyond one year of graduation. Results indicate that in spite of these recommendations, a majority of candidates are choosing to take BEC first. This study notes that pass rates for BEC are the highest of the four exam parts regardless of whether student take the exam within or beyond one year of graduation. It further notes that pass rates for FAR decline from the second highest of the four sections to the lowest of the four sections when comparing candidates taking within one year of graduation to candidates delaying a year or more. This provides additional evidence to suggest that candidates wishing to maximize their chance for success should not only take the FAR section of the CPA exam first but should also take the exam section as soon as possible after graduation. Accounting educators should work with students to develop a plan for completing the CPA Exam that maximizes their opportunities for success. Encouraging students to take the CPA Exam within one year of graduation and to take the FAR section first appears to be the combination that gives students the best chance at successfully completing the CPA Exam as soon as possible. 


\section{REFERENCES}

American Institute of Certified Public Accountants (AICPA). (2020). 150 Hour Requirement for Obtaining a CPA License. Retrieved April 2020 from https://www.aicpa.org/becomeacpa/licensure/requirements.html\#states

Association to Advance Collegiate Schools of Business International (AACSB). (2021). Retrieved from http://aacsb.edu

Becker CPA Review Blog. (2020). The best order for taking the CPA Exam: Why you should go FAR first. Retrieved from https://www.becker.com/blog/cpa/the-best-order-for-taking-the-cpa-examwhy-you-should-go-far-first

Bline, D.M., Perreault, S., \& Zheng, X. (2016a). An exploratory examination of order effects on CPA exam passage timeliness. Journal of Accounting Education, 36, 65-74.

Bline, D.M., Perreault, S., \& Zheng, X. (2016b). Do Accounting Faculty Characteristics Impact CPA Exam Performance? An Investigation of Nearly 700,000 Examinations. Issues in Accounting Education, 31(3), 291-300.

Bunker, R.B., \& Cagle, C.S. (2020). Does Timing Impact Candidate Success on the CPA Exam? Journal of Higher Education Theory and Practice, 20(7), 149-154.

Conteh, L.J., \& Oke, O. (2019). An Examination of the Pass Rates on the CPA Exam: A Suggested Redesign of the Accounting Curriculum 2013-2017. Journal of Higher Education Theory and Practice, 19(6), 49-63.

Eames, M., Luttman, S., \& Parker, S. (2018). Accelerated vs. traditional accounting education and CPA exam performance. Journal of Accounting Education, 44, 1-13.

Gaynor, G., \& Askew, S. (2017). How accounting programs can help students pass the CPA Exam. Journal of Accountancy, 224(3), 16-18.

Marts, J.A., Baker, J.D., \& Garris, J.M. (1988, Fall). Success on the CPA examination in AACSB accredited and non-accredited schools. The Accounting Educators' Journal, 1, 97-105.

Menk, K.B., Nagle, B.M., \& Rau, S.E. (2017). Does Earning a Graduate Degree Impact CPA Exam Performance? Academy of Business Research Journal, 1, 27-42.

Nagle, B.M., Menk, K.B., \& Rau, S.E. (2018, December). Which accounting program characteristics contribute to CPA exam success? A study of institutional factors and graduate education. Journal of Accounting Education, 45, 20-31.

Rau, S.E., Nagle, B.M., \& Menk, K.B. (2019). CPA Exam Performance: The Effect of Graduate Education and Accounting Faculty Credentials. The CPA Journal, 89(9), 42-47.

Romero, E.J. (2008). AACSB Accreditation: Addressing Faculty Concerns. Academy of Management Learning \& Education, 7(2), 245-255.

Shough, E.M., Stetson, B., Walton, A.L., \& Tankersley, K. (2018). MACC curriculum and CPA exam passage rates: An exploratory study. Administrative Issues Journal, 8(2), 94-105.

Ugrin, J.C., \& Honn, D.D. (2018). Advanced placement and CPA exam performance: Implications for recruitment of quality students into college accounting programs. Advances in Accounting, 42, 96-109. 